\title{
Electrocatalytic four-electron reduction of oxygen to water by a highly flexible cofacial cobalt bisporphyrin
}

\author{
Christopher J. Chang, ${ }^{a}$ Yongqi Deng, ${ }^{a}$ Chunnian Shi, ${ }^{b}$ C. K. Chang, ${ }^{* c}$ Fred C. Anson*b and \\ Daniel G. Nocera*a \\ a Department of Chemistry, 6-335, Massachusetts Institute of Technology, 77 Massachusetts Avenue, Cambridge, \\ Massachusetts 02139,USA. E-mail: nocera@mit.edu \\ ${ }^{b}$ Division of Chemistry and Chemical Engineering, Arthur Amos Noyes Laboratory, California Institute of \\ Technology, Pasadena, California 91125, USA \\ c Department of Chemistry, Michigan State University, East Lansing, Michigan 48824, USA
}

\section{Received (in Bloomington, IN, USA) 16th February 2000, Accepted 11th April 2000 \\ Published on the Web 5th July 2000}

\begin{abstract}
Dicobalt(II) cofacial bisporphyrins anchored by dibenzofuran (DPD) and xanthene (DPX) are efficient electrocatalysts for the four-electron reduction of oxygen to water despite their $c a .4 \AA$ difference in metal-metal distances, suggesting that the considerable longitudinal 'Pac-Man' flexibility of the pillared platforms is the origin for the similar catalytic reactivity of these structurally disparate systems.
\end{abstract}

Enzymatic systems are remarkable in their ability to accommodate the large range of motion required for the binding and catalysis of small molecules. In many cases, the kinetic steps of the processes involved are ultimately predicated on conformational changes of the active site upon substrate binding, activation, and/or product release. An outstanding example is the binding and biological reduction of dioxygen to water by cytochrome $c$ oxidase $(\mathrm{C} c \mathrm{O}) .{ }^{1}$ The critical $\mathrm{O}-\mathrm{O}$ bond cleavage chemistry is mediated by a flexible, dinuclear iron-heme/ copper $\left(\mathrm{Fe}_{\mathrm{a} 3} / \mathrm{Cu}_{\mathrm{B}}\right)$ assembly. ${ }^{1,2}$ Nevertheless, the pursuit of structural and functional models for $\mathrm{O}_{2}$ activation have emphasized, for the most part, bimetallic reaction centers poised within well-defined, rigid pockets. ${ }^{3-7}$ For example, pillared cofacial dicobalt bisporphyrins bridged by anthracene (DPA) and biphenylene (DPB) ${ }^{8-11}$ impair ring slippage, and as a result, these complexes efficiently electrocatalyze the direct fourelectron reduction of oxygen to water (as opposed to the twoelectron pathway involving peroxide) with little structural reorganization of juxtaposed subunits. Can efficient oxygenactivation chemistry be preserved when this cofacial structural motif exhibits a large range of motion? To address this issue, we have developed methods for the facile assembly of new cofacial bisporphyrins, incorporating dibenzofuran (DPD) ${ }^{12}$ or xanthene $(\mathrm{DPX})^{13}$ pillars that exhibit variable pocket sizes with minimal lateral displacements. Herein, we report that dicobalt(II) complexes of both DPD and DPX efficiently mediate the direct four-electron reduction of oxygen to water despite a $c a$. $4 \AA$ difference in their metal-metal distances (as determined from their X-ray crystal structures), suggesting that the longitudinal 'Pac-Man' flexibility of these molecular clefts allows the designed binding pocket to structurally accommodate reaction intermediates during multielectron catalysis.

$\mathrm{Co}_{2}$ (DPD) 1 was obtained in excellent yield (91\%) from reaction of the corresponding free base bisporphyrin with $\mathrm{CoCl}_{2}$ and 2,6-lutidine. $\dagger$ Crystals suitable for X-ray diffraction studies were grown from dichloromethane-methanol solutions. $\ddagger$ The structure of 1 (Fig. 1) shows that two methanol solvent molecules are coordinated inside the bisporphyrin pocket to the two cobalt(II) centers. In order to accommodate the two exogeneous ligands, the DPD framework opens its 'bite' considerably. The interplanar angle between the two macrocycles is $56.5^{\circ}$, resulting in metal-metal $(8.624 \AA)$ and center- to-center $(8.874 \AA)$ distances that are markedly larger than found in $\mathrm{Zn}_{2}(\mathrm{DPD})\left(d_{\mathrm{Zn}-\mathrm{Zn}}=7.775 \AA, d_{\mathrm{Ct}-\mathrm{Ct}}=7.587 \AA\right) .{ }^{12}$

The $\mathrm{Co}(\mathrm{II})$ cores adopt an approximate square-pyramidal geometry, as the $\mathrm{N}-\mathrm{Co}-\mathrm{N}$ bond angles are $90 \pm 1.3^{\circ}$ and the $\mathrm{N}-$ $\mathrm{Co}-\mathrm{O}$ bond angles are $90 \pm 5.3^{\circ}$. The Co centers are displaced slightly from the porphyrin meanplane $\left(d_{\mathrm{av}}=0.1355 \AA\right)$ toward the axial ligand. The average axial Co-O bond length $(2.272 \AA)$ is significantly longer than that of the average equatorial Co-N bond ( $1.982 \AA$ ), owing to the occupancy of the $\mathrm{d}_{z 2}$ orbital by a single unpaired electron in $\mathrm{Co}(\mathrm{II})$. A conformational analysis of the two macrocycles indicates inequivalent ring systems. The porphyrin ring containing $\operatorname{Co}(1)$ exhibits an $S_{4}$ ruffle with a mean deviation from planarity of $0.1416 \AA$. In contrast, the ring with $\mathrm{Co}(2)$ is essentially flat (average deviation $0.0307 \AA$ ). Lastly, the most important structural feature of $\mathbf{1}$ in relation to its $\mathrm{O}_{2}$ reactivity (vide infra) is the small tortional twist $\left(9.3^{\circ}\right.$, defined as the torsion angle between the two meso-carbon to
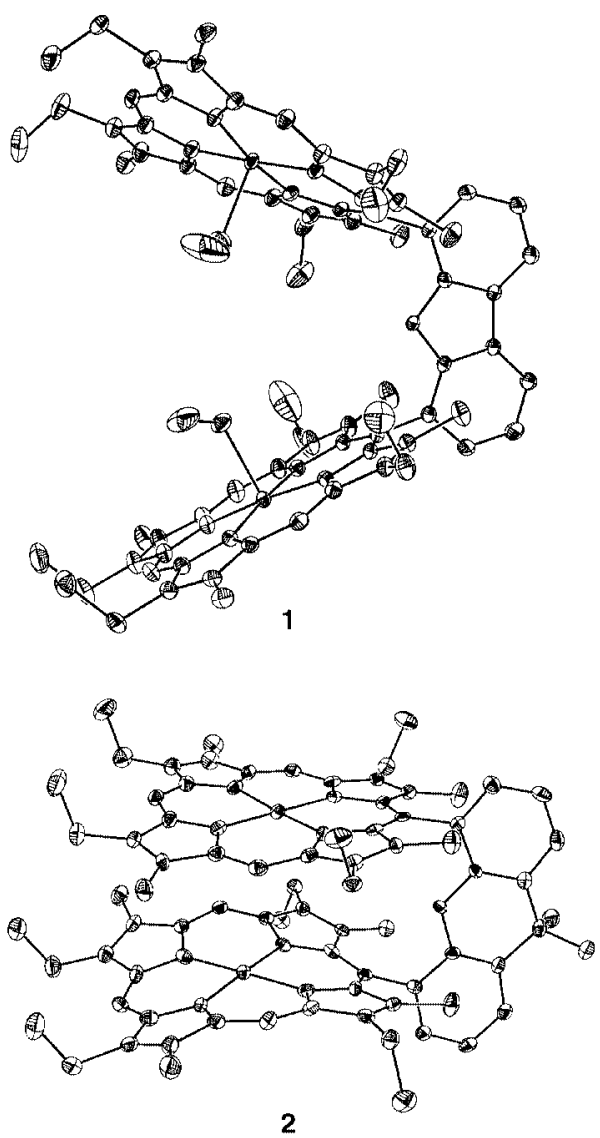

Fig. 1 Molecular structures of $\mathbf{1}$ and $\mathbf{2}$ with hydrogen atoms omitted for clarity. Thermal ellipsoids are drawn at the $30 \%$ probability level. 


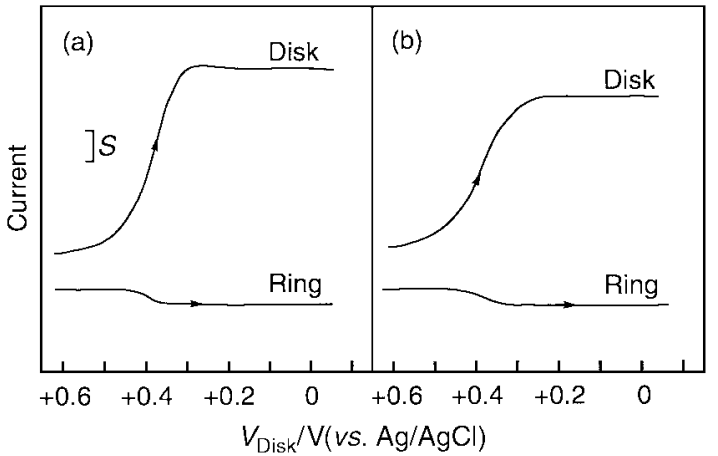

Fig. 2 Rotating $\mathrm{Pt}$ ring-disk voltammograms for reduction of $\mathrm{O}_{2}$ at pyrolytic graphite disks coated with (a) $\mathbf{1}$ and (b) 2. Rotation rate, $100 \mathrm{rpm}$; disk current, $S=10 \mu \mathrm{A}$; ring current, $S=5 \mu \mathrm{A}$; supporting electrolyte, $0.5 \mathrm{M}$ $\mathrm{HClO}_{4}-1.5 \mathrm{M} \mathrm{CF}_{3} \mathrm{CO}_{2} \mathrm{H}$ saturated with air.

spacer bonds) between the porphyrinic subunits, giving a cofacial binding pocket with a directed longitudinal reaction coordinate for substrate binding and activation.

Cyclic voltammograms of $\mathbf{1}$ in nitrobenzene give a single, reversible oxidative wave at $+0.33 \mathrm{~V}$ ( $v s$. $\mathrm{AgCl} / \mathrm{Ag})$, consistent with two non-interacting metal centers. The complex was screened as an electrocatalytst for the reduction of dioxygen. ${ }^{14,15}$ Fig. 2(a) displays a rotating ring-disk voltammogram for the reduction of $\mathrm{O}_{2}$ at a graphite electrode coated with $\mathbf{1}$. Remarkably, 1 catalyzes the reduction of oxygen at the unusually positive potential of $0.37 \mathrm{~V}$ ( $v s$. $\mathrm{AgCl} / \mathrm{Ag}$ ) with $80 \%$ of the $\mathrm{O}_{2}$ reduction proceeding along the four-electron pathway to produce water; the longitudinal 'Pac-Man' flexibility of this molecular cleft apparently allows it to 'bite' down on the $\mathrm{O}_{2}$ substrate resulting in efficient catalytic activation.

We sought to compare the reactivity of $\mathbf{1}$ to a dicobalt(II) cofacial complex where the bite size of the cleft is preorganized for oxygen activation. The six-membered center ring of the xanthene spacer of $\mathrm{Co}_{2} \mathrm{DPX} \mathbf{2} \dagger$ causes the two porphyrin macrocycles to bend slightly in toward each other (Fig. 1), giving a mean interplanar distance of $3.519 \AA$ A between the two porphyrin rings, + which is quite similar to that found in $\mathrm{Co}_{2}$ DPB $(3.381 \AA) .{ }^{10,11}$ However, the torsional twist $\left(21.1^{\circ}\right)$ between the two rings results in a metal-metal distance of 4.582 $\AA\left(\mathrm{Co}_{2} \mathrm{DPB}, 3.726 \AA\right)$. The square geometry for the $\mathrm{Co}$ (II) cores is confirmed by the $\mathrm{N}-\mathrm{Co}-\mathrm{N}$ bond angles of $90 \pm 1.7^{\circ}$. As observed for $\mathbf{1}$ and for other structurally characterized DPX metal complexes, ${ }^{13}$ the two ring systems of $\mathbf{2}$ are structurally inequivalent in the solid state. The macrocycle with $\mathrm{Co}(1)$ exhibits a pronounced ruffled conformation with a mean deviation from planarity of $0.2227 \AA$, while the macrocycle containing $\operatorname{Co}(2)$ has a less pronounced ruffle with a mean deviation from planarity of $0.1118 \AA$. The more compressed structure of $\mathbf{2}$ engenders mixed-valence behavior, as two reversible electrochemical oxidations are observed at +0.28 and $+0.17 \mathrm{~V}$; the $\mathrm{Co}$ (II)/Co(III) DPX complex reacts with dioxygen in the presence of 1,5-dicyclohexylimidazole to give a 15-line EPR spectrum typical of a symmetrical biscobalt(III) superoxo complex $\left(g=2.02, A_{\mathrm{Co}}=11.14 \mathrm{G}\right) .^{8-10}$ Nevertheless, 2 efficiently catalyzes the reduction of oxygen at a potential $(0.38$ $\mathrm{V}$ vs. $\mathrm{AgCl} / \mathrm{Ag}$ ) and with a selectivity for the four-electron pathway to produce water $(72 \%)$ commensurate to $\mathbf{1}$ [Fig. 2(b)].

The observation that both complexes are efficient catalysts for the four-electron reduction of oxygen to water, despite their notable differences in structure and redox behavior, is striking. The results suggest that the longitudinal open-to-closed conformational change in the presence of oxygen, especially dramatic in the DPD framework, involves only a small change in conformational energy. The structure of the bisiron(III) $\mu$-oxo complex of DPD provides further evidence of the 'Pac-Man' effect, as the framework readily closes its structure to give a complex with a compressed metal-metal distance of $3.504 \AA \AA^{12}$ Accordingly, the conformational flexibility of these 'Pac-Man' porphyrins provides a directed reaction coordinate for facile substrate activation and product release. With the synthetic availability of both the DPD and DPX frameworks, we are poised to incisively investigate structural and electronic effects on the small-molecule reactivity of these pillared cofacial bisporphyrins. Current studies are aimed at photoactivating the dioxygen molecule to address mechanistic issues concerning the proton-coupled $\mathrm{O}-\mathrm{O}$ bond cleavage chemistry ${ }^{16}$ of these and related complexes.

C. J. C. gratefully acknowledges the National Science Foundation for a predoctoral fellowship. We thank A. Heyduk for help with the X-ray crystallography. This work was supported by the National Institutes of Health GM 47274.

\section{Notes and references}

$\dagger$ Complexes $\mathbf{1}$ and $\mathbf{2}$ were prepared by metallation of the appropriate cofacial bisporphyrin with $\mathrm{CoCl}_{2}$ and 2,6-lutidine in refluxing THF. X-Ray quality crystals were obtained from slow evaporation of dichloromethane/ methanol solutions. Characterization data: 1: $\mathrm{C}_{76} \mathrm{H}_{76} \mathrm{Co}_{2} \mathrm{~N}_{8} \mathrm{O}$ : calc. C, 73.89; H, 6.20; N, 9.54; found $\mathrm{C}, 73.82 ; \mathrm{H}, 6.26 ; \mathrm{N}, 8.94 \%$. HRFABMS $\left(\mathrm{M}^{+}\right)$: calc. $\mathrm{m} / z$ 1234.4806; found: 1234.4801 . 2: $\mathrm{C}_{79} \mathrm{H}_{82} \mathrm{Co}_{2} \mathrm{~N}_{8} \mathrm{O}$ : calc. C, 74.24; H, 6.47; N, 8.77; found: C, 73.86; H, 6.42; N 8.71\%. HRFABMS $\left(\mathrm{M}^{+}\right)$: calc. $\mathrm{m} / \mathrm{z}$ 1276.5276; found 1276.5257 .

$\$$ Crystal data: 1 : $\mathrm{C}_{80} \mathrm{H}_{84} \mathrm{Cl}_{2} \mathrm{Co}_{2} \mathrm{~N}_{8} \mathrm{O}_{4}, M=1410.31$, triclinic, space group $P \overline{1}, a=10.9872(2), b=13.0824(2), c=27.2127(10) \AA, \alpha=84.68, \beta=$ 87.2850(10), $\gamma=71.8840(10)^{\circ}, U=3700.93(9) \AA^{3}, Z=2, D_{\mathrm{c}}=1.266 \mathrm{~g}$ $\mathrm{cm}^{-3}$. A total of 15393 reflections were collected in the $\theta$ range $1.50-$ $23.68^{\circ}$ at $183(2) \mathrm{K}$ on a Siemens SMART CCD diffractometer, of which 10494 were unique $\left(R_{\mathrm{int}}=0.0334\right)$. The largest peak and hole in the

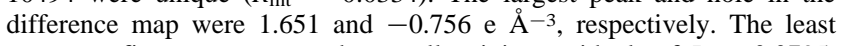
squares refinement converged normally giving residuals of $R=0.0795$, $w R 2=0.2186$, and GOF $=1.121 .2: \mathrm{C}_{79} \mathrm{H}_{82} \mathrm{Co}_{2} \mathrm{~N}_{8} \mathrm{O}_{2}, M=1277.39$, monoclinic, space group $C 2 / c, a=24.1310(5), b=10.6260(2), c=$ $50.2717(10) \AA, \beta=99.5120(10)^{\circ}, V=12713.2(4) \AA^{3}, Z=8, D_{c}=1.335$ $\mathrm{g} \mathrm{cm}^{-3}$. A total of 25472 reflections were collected in the $\theta$ range $1.64-23.42^{\circ}$ at $183(2) \mathrm{K}$, of which 9225 were unique $\left(R_{\text {int }}=0.1088\right)$. The largest peak and hole in the difference map were 0.445 and -0.461 e $\AA^{-3}$, respectively. The least squares refinement converged normally giving residuals of $R=0.0829, w R 2=0.1479$, and GOF $=1.149$.

CCDC 182/1685. See http://www.rsc.org/suppdata/cc/b0/b001620i/ for crystallographic files in .cif format

1 H. Michel, J. Behr, A. Harrenga and A. Kannt, Annu. Rev. Biophys. Biomol. Struct., 1998, 27, 329.

2 S. Ferguson-Miller and G. T. Babcock, Chem. Rev., 1996, 96, 2889.

3 J. P. Collman, M. Rapta, M. Bröring, L. Raptova, R. Schwenninger, B. Boitrel, L. Fu and M. L'Her, J. Am. Chem. Soc., 1999, 121, 1387.

4 J. P. Collman, L. Fu, P. C. Herrmann, Z. Wang, M. Rapta, M. Broring, R. Schwenninger and B. Boitrel, Angew. Chem., Int. Ed., 1998, 37, 3397.

5 J. O. Baeg and R. H. Holm, Chem. Commun., 1998, 571.

6 H. C. Liang, M. Dahan and K. D. Karlin, Curr. Opin. Chem. Biol., 1999, 3, 168.

7 D. Ricard, B. Andrioletti, M. L'Her and B. Boitrel, Chem. Commun., 1999, 1523.

8 C. K. Chang and I. Abdalmuhdi, Angew. Chem., Int. Ed. Engl., 1984, 23, 164.

9 C. K. Chang, H. Y. Liu and I. Abdalmuhdi, J. Am. Chem. Soc., 1984, 106, 2725 .

10 J. P. Collman, J. E. Hutchinson, M. A. Lopez, A. Tabard, R. Guilard, W. K. Seok, J. A. Ibers and M. L'Her, J. Am. Chem. Soc., 1992, 114, 9869.

11 J. P. Collman, P. S. Wagenknecht and J. E. Hutchinson, Angew. Chem., Int. Ed. Engl., 1994, 33, 1537.

12 Y. Deng, C. J. Chang and D. G. Nocera, J. Am. Chem. Soc., 2000, 122, 410.

13 C. J. Chang, Y. Deng, A. F. Heyduk, C. K. Chang and D. G. Nocera, Inorg. Chem., 2000, 39, 959.

14 F. C. Anson, C. Shi and B. Steiger, Acc. Chem. Res., 1997, 30, 437.

15 M. Yuasa, B. Steiger and F. C. Anson, J. Porphyrins Phthalocyanines, 1997, 1, 181.

16 R. I. Cukier and D. G. Nocera, Аnnu. Rev. Phys. Chem., 1998, 49, 337. 